\title{
Unusual Zig-Zag Effect in the Electrochemical Oxidation of Phenyl End-Capped $\alpha$-Oligothiophenes
}

\author{
Kevin Bold ${ }^{\mathrm{a}}$ \\ Matthias Stolte ${ }^{a, b}$ \\ Frank Würthner*a,b (iD \\ ${ }^{a}$ Institut für Organische Chemie, Universität Würzburg, Am Hubland, 97074 \\ Würzburg, Germany \\ ${ }^{\mathrm{b}}$ Center for Nanosystems Chemistry, Universität Würzburg, Theodor-Boveri-Weg, \\ 97074 Würzburg, Germany \\ wuerthner@uni-wuerzburg.de \\ Dedicated to Professor Peter Bäuerle on the occasion of his 65th birthday.
}

Received: 16.01.2021

Accepted: 27.01.2021

DOI: 10.1055/s-0041-1726089; Art ID: om-21-0009oa

License terms: CC)

(c) 2021. The Author(s). This is an open access article published by Thieme under the terms of the Creative Commons Attribution-NonDerivative-NonCommercial License, permitting copying and reproduction so long as the original work is given appropriate credit. Contents may not be used for commercial purposes, or adapted, remixed, transformed or built upon. (https://creativecommons.org/licenses/by-nc-nd/4.0/)

Abstract A series of phenyl end-capped $\alpha$-oligothiophenes containing four to seven thiophene subunits (4T-7T) was synthesized utilizing palladium-catalyzed cross-coupling reactions. UV/Vis spectroscopic analysis revealed one broad absorption band that shifts bathochromically with increasing number of thiophene units. Structured emission spectra are observed with Stokes shift $>4000 \mathrm{~cm}^{-1}$ and quantum yields of up to $53 \%$. End-capping of the oligothiophene molecules by phenyl units does not only extend the effective conjugation but also prevents from $\alpha-\alpha$-homocoupling upon electrochemical oxidation. Accordingly, reversible redox waves are observed in cyclic voltammetry with up to four reversible one-electron processes for the two longer congeners. Analyses of the first two oxidation processes in the framework of multiredox systems provide insight into the stabilization or destabilization of polaronic and bipolaronic states. An unusual zig-zag trend for the first (and to a lesser extend second) oxidation process could be explained by the sterical encumbrance of solubilizing hexyl chains in $\mathbf{5 T}$ and 7T molecules which counteract the formation of a fully planar quinoidal oligothiophene backbone.

Key words oligothiophenes, multiredox systems, spectroscopy, sterical congestion

\section{Introduction}

In the 1990s oligo- and polythiophenes advanced to the most important class of materials for organic electronics. ${ }^{1}$ Different from other classes of compounds such as the acenes, pentacene being the most important representative, ${ }^{2}$ or a variety of (semi-)conducting polymers such as polyacetylene or polyaniline, highly successful materials containing (oligo-) thiophene were developed both for small molecules and for polymers. ${ }^{3}$ Further, this class of compounds proved to

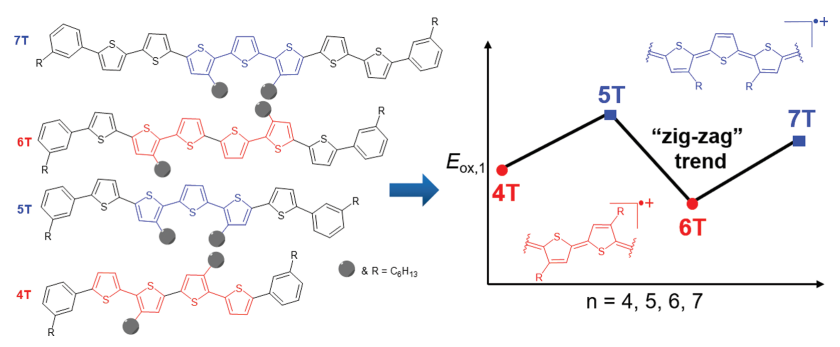

perform well and to be sufficiently stable in a large variety of applications including conducting polymers such as poly (3,4-ethylenedioxythiophene $)^{4,5}$ as transparent conductive interlayers or low-molecular-weight oligothiophene-based organic semiconductors for applications in field effect transistors ${ }^{6}$ and organic solar cells. ${ }^{7}$ Whilst all successful oligo- and polythiophene molecules rely on the connection of the thiophene units in 2,5-( $\alpha$ ) positions, either accessible by electropolymerization ${ }^{8}$ or chemical synthesis, ${ }^{9}$ the length and position of alkyl chains proved to be of significant importance for the ordering of the molecules in the solid state where interdigitation of alkyl chains plays a major role. Further, despite the fact that the conformational equilibrium between cis and trans orientations of the neighboring thiophene units was noted already early, ${ }^{10}$ it took until 2000 that Bäuerle and coworkers demonstrated by scanning tunneling microscopy studies how $180^{\circ}$ turns of a polythiophene chain could be realized on highly oriented pyrolytic graphite surfaces by about eight thiophenes in the cis orientation. ${ }^{11}$ In the same year, the Bäuerle group could also synthesize the first fully conjugated (macro)cyclic $\alpha$-conjugated oligothiophenes containing 12 to 18 thiophene units. ${ }^{12}$ With their improved synthetic methodology, later on also larger cyclo[ $n$ ]oligothiophenes became reality. ${ }^{13}$

Nevertheless, albeit with such impressive work the existence of conformational equilibria between cis- and trans-oriented conformers and the concomitant establishment of a curvature due to significant amounts of the cis conformers have been demonstrated; the impact of the respective positioning of alkyl substituents with respect to each other on the cis/trans equilibria and on the $\pi$-conjugation remains not fully understood. ${ }^{14}$ This problem relates to the fact that oligo-and polythiophenes are not rigid in the ground state but prevail as rotameric mixtures with low rotation barriers of only $1-2 \mathrm{kcal} / \mathrm{mol} .{ }^{15}$ Also it has been consistently reported that the cis and trans conformers are nonplanar in solution. In contrast, the vast majority of oligothiophene single crystals reveal fully planar all-trans geometries (in few cases a cis-orientation has been observed in particular for the terminal bithiophene units), ${ }^{16}$ which is obviously the result of 
packing forces. However, also in solution both the optically excited and the oxidized states are significantly more planar due to an increased quinoid character, i.e. double bond formation between the thiophene units. ${ }^{17,18}$ In this paper we will investigate some unusual effects that are revealed by electrochemical oxidation depending on the position of the solubilizing alkyl chains.

\section{Results and Discussion}

The oligothiophene series 4T-7T was synthesized following stannylation reactions employing lithiated oligothiophenes $\mathbf{1}, \mathbf{3}, \mathbf{5}$, or $\mathbf{7}$ and $\mathrm{Sn}\left(\mathrm{C}_{4} \mathrm{H}_{9}\right)_{3} \mathrm{Cl}$ as a tin source, and subsequent palladium-catalyzed Stille cross-coupling protocols with 1-bromo-3-hexylbenzene (Scheme 1). ${ }^{19}$ All compounds were characterized by NMR spectroscopy and HRMS. Redox potentials were determined using cyclic voltammetry (CV) and differential pulse voltammetry (DPV) in $\mathrm{CH}_{2} \mathrm{Cl}_{2}$. Optical characterization was conducted using UV/Vis absorption and fluorescence spectroscopy in $\mathrm{CH}_{2} \mathrm{Cl}_{2}$ as well.

The basic $\alpha$-oligothiophene backbone design involved modifications by two hexyl chains attached in three different regioisomeric relationships with each other. ${ }^{20}$ Accordingly, the central terthiophene unit of $\mathbf{5 T}$ and $\mathbf{7 T}$ was equipped

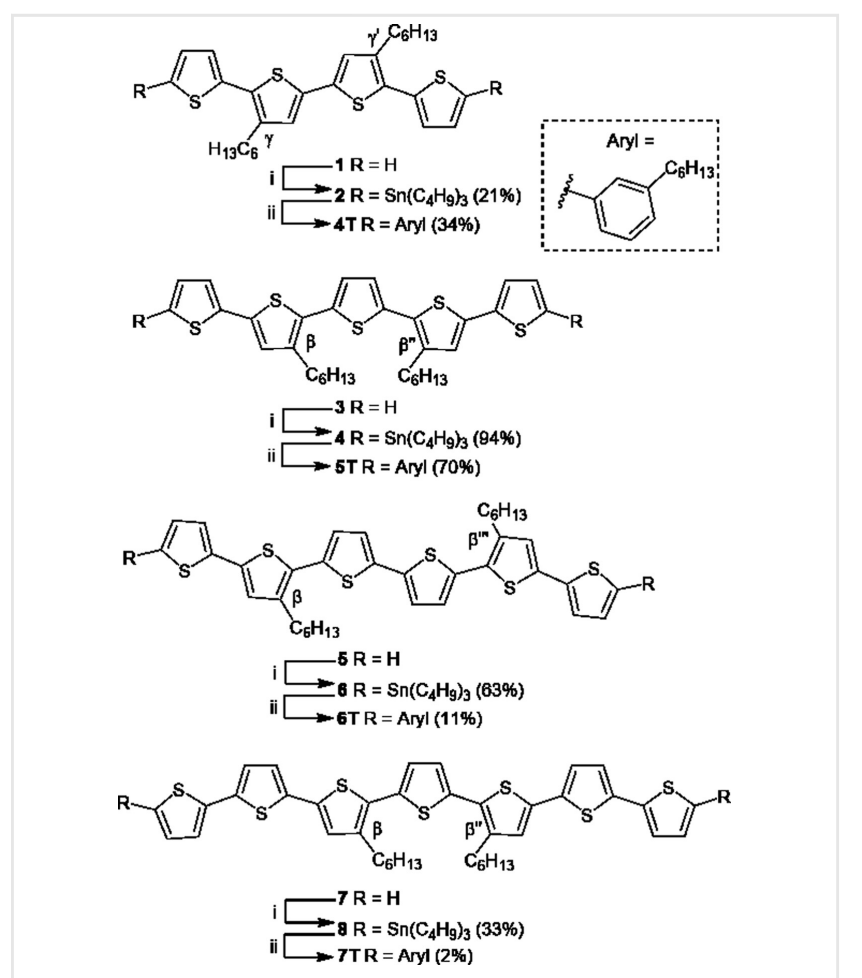

Scheme 1 Synthesis of the phenyl end-capped oligothiophene compounds 4T-7T. i) $\mathrm{Sn}\left(\mathrm{C}_{4} \mathrm{H}_{9}\right)_{3} \mathrm{Cl}$, n-BuLi, TMEDA, THF or $\mathrm{Et}_{2} \mathrm{O}$. ii) 1-Bromo3-hexylbenzene, $\left[\mathrm{Pd}_{2} \mathrm{dba}_{3}\right], \mathrm{P}(\mathrm{o} \text {-tolyl })_{3}$, toluene, $95^{\circ} \mathrm{C}$, overnight. dba = dibenzylideneacetone, TMEDA $=$ tetramethylethylenediamine. with two aliphatic chains in $\beta, \beta^{\prime \prime}$-positions, whereas in $\mathbf{6 T}$ the aliphatic chains are located at the spatially more separated $\beta, \beta^{\prime \prime \prime}$-positions (Scheme 1). Contrarily, in compound 4T the focal bithiophene center is equipped with two hexyl chains in $\gamma, \gamma^{\prime}$-positions. The above-described positioning of the alkyl chains is of major importance for the structure-property relationship discussion below. Supported by the two alkyl chains of the terminal benzene units, all of these oligothiophenes exhibit sufficient solubility to enable the optical and electrochemical experiments conducted in this work. The end-capping by phenyl units proved to be successful to protect the central oligothiophene units against subsequent oxidative coupling reactions as typically observed for the most reactive free $\alpha$-positions of oligothiophenes. ${ }^{8}$

Oligothiophenes 4T-7T show one main broad and unstructured absorption band in $\mathrm{CH}_{2} \mathrm{Cl}_{2}$ corresponding to the lowest energy $\pi-\pi^{*}$ transition where an electron is promoted from the HOMO to the LUMO level. ${ }^{14}$ The gradual increase of the number of thiophene subunits within the series from 4T to 7T leads to a bathochromic shift of the absorption maxima $\left(\lambda_{\mathrm{abs}}\right)$ from $413 \mathrm{~nm}$ for $\mathbf{4 T}$ up to $444 \mathrm{~nm}$ for 7T (Figure 1).

The common procedure to evaluate conjugation along $\pi$-conjugated oligomeric backbones, i.e. correlating the electronic band gap (here approximated by the absorption maxima $\lambda_{\max }$ ) and the inverse number of thiophene units, ${ }^{21}$ reveals nothing special compared to other oligothiophene series studied in the past (Figure S1). ${ }^{22-24}$ This can be taken as an indication that the conformation of the oligothiophene chain with regard to the equilibrium of cis/trans rotamers and the average twist angle between the thiophene units are not unusual for 4T-7T in their electronic ground states. In accordance with previous work, also the extinction coefficients are increased upon $\pi$-core extension from

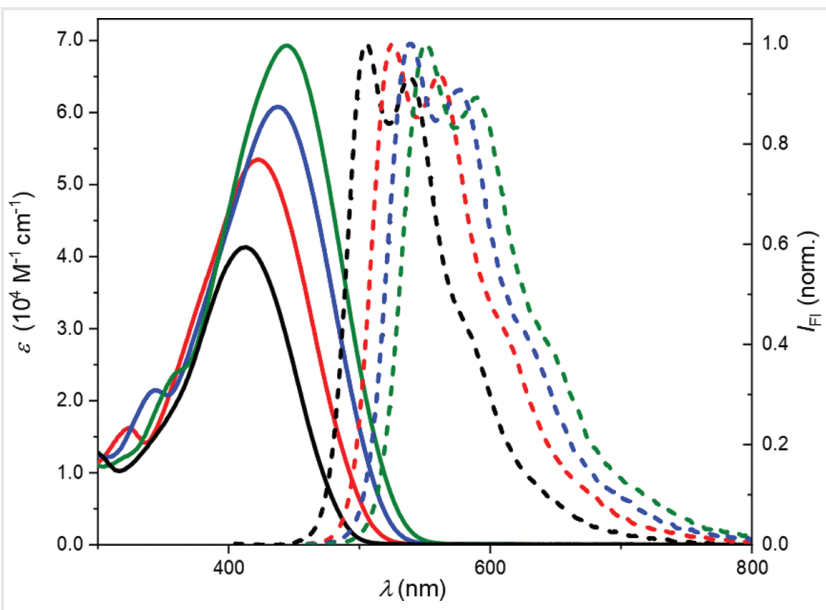

Figure $1 \mathrm{UV} / \mathrm{Vis}$ absorption (solid lines, $c_{0}=10^{-5} \mathrm{M}$ ) and normalized emission spectra (dashed lines, $\lambda_{\mathrm{ex}}=400 \mathrm{~nm}, c_{0}=10^{-7} \mathrm{M}$ ) of $\mathbf{4 T}$ (black), 5T (red), 6T (blue), and 7T (green) in dichloromethane at room temperature. 
Table 1 Absorption, fluorescence, and electrochemical data of 4T-7T in $\mathrm{CH}_{2} \mathrm{Cl}_{2}$ at room temperature

\begin{tabular}{lllll}
\hline & $\mathbf{4 T}$ & $\mathbf{5 T}$ & $\mathbf{6 T}$ & $\mathbf{7 T}$ \\
\hline$\lambda_{\mathrm{abs}, \mathrm{max}} \mathrm{T} / \mathrm{nm}$ & 413 & 422 & 437 & 444 \\
$\varepsilon_{\max } / 10^{3} \mathrm{M}^{-1} \mathrm{~cm}^{-1}$ & 41.3 & 53.5 & 60.8 & 69.3 \\
$\lambda_{\mathrm{em}, \max } \mathrm{b} / \mathrm{nm}$ & 505 & 526 & 538 & 551 \\
$\tilde{V}_{\text {stokes }} / \mathrm{cm}^{-1}$ & 4530 & 4740 & 4240 & 4370 \\
$\Phi_{\mathrm{fl}}{ }^{\mathrm{c}} / \%$ & 40 & 53 & 49 & 46 \\
$T_{\mathrm{ff}}{ }^{\mathrm{d}} / \mathrm{ns}$ & 0.74 & 0.88 & 0.79 & 0.77 \\
$E_{\mathrm{ox}, 1}{ }^{\mathrm{e}} / \mathrm{V}$ & 0.33 & 0.41 & 0.16 & 0.24 \\
$E_{\mathrm{ox}, 2}{ }^{\mathrm{e}} / \mathrm{V}$ & 0.58 & 0.59 & 0.34 & 0.43 \\
$E_{\mathrm{ox}, 3}{ }^{\mathrm{e}} / \mathrm{V}$ & - & - & 0.96 & 0.88 \\
$E_{\mathrm{ox}, 4}{ }^{\mathrm{e}} / \mathrm{V}$ & - & - & 1.21 & 1.12 \\
$E_{\mathrm{ox}, 2}-E_{\mathrm{ox}, 1} / \mathrm{V}$ & 0.25 & 0.18 & 0.18 & 0.19 \\
\hline
\end{tabular}

${ }^{\mathrm{a}} \mathrm{C}_{0}=10^{-5} \mathrm{M}$.

${ }^{\mathrm{b}} \mathrm{\lambda}_{\mathrm{ex}}=400 \mathrm{~nm}, \mathrm{c}_{0}=10^{-7} \mathrm{M}$.

${ }^{\mathrm{C}}$ The fluorescence quantum yields were measured relative to perylene ${ }^{27}$ as a reference at four different excitation wavelengths.

${ }^{d}$ For lifetime measurements a pulsed laser diode with a wavelength of $403.8 \mathrm{~nm}$ was utilized.

${ }^{\mathrm{e}} C_{0}=10^{-4} \mathrm{M}, \mathrm{Bu}_{4} \mathrm{NPF}_{6}$ was used as a conducting salt; all values are referenced against the ferrocenium/ferrocene $\left(\mathrm{Fc}^{+} / \mathrm{Fc}\right)$ redox couple.

$41300 \mathrm{M}^{-1} \mathrm{~cm}^{-1}$ for 4T up to $69300 \mathrm{M}^{-1} \mathrm{~cm}^{-1}$ for 7T (Table 1). ${ }^{25}$ However, compared to the respective non-endcapped $\alpha$-oligothiophenes, ${ }^{14,22}$ the two additional phenyl caps lead to an enhanced red shift of about $30-40 \mathrm{~nm}$ (1750-2700 $\mathrm{cm}^{-1}$ ), which suggests that they extend the HOMOs and LUMOs as well as the transition dipole moments of the conjugated oligothiophene $\pi$-scaffolds. Indeed, $6 \mathbf{T}$ exhibits an absorption maximum at $437 \mathrm{~nm}$ that almost corresponds to the one observed for a similar fouralkyl-chain-solubilized octithiophene $\left(\lambda_{\mathrm{abs}, \max }=439 \mathrm{~nm}\right)$ reported by Bäuerle and co-workers. ${ }^{26}$

In contrast to the broad and unstructured absorption spectra, the fluorescence spectra of $4 \mathrm{~T}-7 \mathrm{~T}$ in $\mathrm{CH}_{2} \mathrm{Cl}_{2}$ show vibronic patterns with two clearly distinguishable emission maxima $\left(\lambda_{\mathrm{em}, \max }\right)$ at a distance of about $50 \mathrm{~nm}\left(1580 \mathrm{~cm}^{-1}\right)$. The appearance of such vibronic patterns originating from aromatic $\mathrm{C}-\mathrm{C}$ stretching modes suggests that 4T-7T molecules are more rigid in their excited states $\left(\mathrm{S}_{1}\right)$ due to more quinoidal structures with pronounced double bond character between the respective thiophene units. ${ }^{22}$ The structural rearrangements of the excited states also cause large Stokes shifts $\left(\tilde{v}_{\text {Stokes }}\right.$ ) of over $4200 \mathrm{~cm}^{-1}$ for all chromophores (Table 1). Further, the emission maxima are bathochromically shifted with increasing number of thiophene units from 4T (505 $\mathrm{nm})$ to $7 \mathbf{T}(551 \mathrm{~nm})$, thereby corroborating the delocalization along the $\pi$-conjugated oligothiophene backbone. However, similar to the absorption maxima, there is also nothing particularly unusual for the positions of the emission maxima $\left(\lambda_{\mathrm{em}, \mathrm{max}}\right)$ upon plotting the band gap for the relaxed excited states against the inverse number of thiophene units (Figure S1). The fluorescence
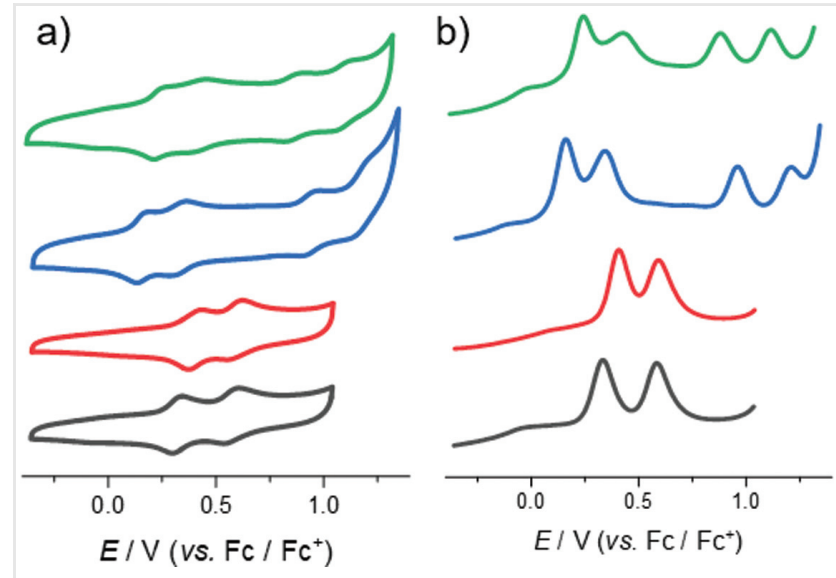

Figure 2 a) CV and b) DPV measurements of 4T (black), 5T (red), 6T (blue), and $7 \mathrm{~T}$ (green) in $\mathrm{CH}_{2} \mathrm{Cl}_{2}$ solutions of $\mathrm{Bu}_{4} \mathrm{NPF}_{6}$ at room temperature $\left(c_{0}=10^{-4} \mathrm{M}\right)$ relative to $\mathrm{Fc}^{+} / \mathrm{Fc}$.

quantum yields $\left(\Phi_{\mathrm{fl}}\right)$ increase from $40 \%$ (4T) to 53\% (5T), while then decreasing with elongation of the $\pi$-system to $46 \%$ (7T), probably due to an increase of nonradiative deactivation pathways as suggested by the energy gap law (Table 1$)^{28}$ Fluorescence lifetimes $\left(\tau_{\mathrm{fl}}\right)$ were determined by timecorrelated single photon counting (TCSPC) with a diode laser at $403.8 \mathrm{~nm}$ and yielded for all oligothiophenes similar values between 0.7 and $1 \mathrm{~ns}$ (Table 1; for details see the Supporting Information, Figure S2).

Insight into the redox properties of this new series of end-capped oligothiophenes 4T-7T was obtained via electrochemical investigations by $\mathrm{CV}$ and $\mathrm{DPV}$ in $\mathrm{CH}_{2} \mathrm{Cl}_{2}$. Electrochemical oxidation of $\alpha$-oligothiophenes is often accompanied by irreversible $\alpha, \alpha^{\prime}$ coupling reactions between the resulting radical cations, leading to longer oligomers and polymers. ${ }^{17}$ The irreversibility of this oxidation process is observed, e.g. in CV experiments, where also additional waves upon radical coupling can be monitored. As shown by Bäuerle, such couplings can, however, be prohibited by either end-capping of the reactive terminal thiophene $\alpha$-positions ${ }^{22}$ or extension of the oligothiophene chain until the radical cation or dication is sufficiently stabilized. ${ }^{29}$ For the here-investigated oligothiophenes 4T-7T that are flanked by a hexylphenyl moiety at both ends, $\mathrm{CV}$ experiments in $\mathrm{CH}_{2} \mathrm{Cl}_{2}$ revealed only reversible oxidation processes (Figure $2 \mathrm{a}$ ).

While 4T and 5T show only two one-electron transfer steps leading to the radical cation and the dication, respectively, for $\mathbf{6 T}$ and $\mathbf{7 T}$ even the subsequent oxidation waves to the tri- and tetracationic species could be detected. This is in accordance with earlier work on oligothiophenes as the number of possible redox states increases with the number of thiophene units and therewith allows for a distribution of the positive charges without the creation of too large repulsive Coulomb forces. ${ }^{14}$ Nevertheless, the 
reversible formation of the three- and fourfold charged species within the solvent window of $\mathrm{CH}_{2} \mathrm{Cl}_{2}$ is typically only observed for higher homologues such as structures bearing 10 thiophene subunits or more. ${ }^{13}$ Accordingly, the observation of these states again corroborates the stabilizing influence of the terminal phenyl units in oligothiophenes 4T-7T. Most interestingly, however, the first oxidation potentials $\left(E_{\mathrm{ox}, 1}\right)$ do not gradually decrease with increasing number of thiophene units in our series 4T-7T, but rather display an unexpected zig-zag trend that will be discussed in detail later.

With the better resolution of the peaks, DPV measurements (Figure $2 \mathrm{~b}$ ) clearly indicate the respective stabilization of cationic versus dicationic species of each oligothiophene. While the two subsequent oxidation processes in the case of 4T are energetically clearly separated by $0.25 \mathrm{~V}$ from each other, with increasing oligothiophene length the waves become more closely spaced by only $0.18 \mathrm{~V}\left(E_{\mathrm{ox}, 2}-E_{\mathrm{ox}, 1}\right.$; Table 1). Similar behavior has been observed for other oligothiophene series, e.g. for Bäuerle's series of oligothiophenes bearing tetramethylene bridges at terminating thiophene units (ECnT) the difference in the redox potentials for the first and second oxidation waves reduces from $0.34 \mathrm{~V}$ for EC4T via 0.29 (EC5T) to $0.19 \mathrm{~V}$ (EC6T). ${ }^{22}$

Whilst the properties of these radical cations and dications were mostly analyzed from the physics perspective on polaron-bipolaron theory, ${ }^{18,22}$ little attention has indeed been devoted to interrelate the difference in these subsequent redox processes to earlier work in chemistry. However, it is easily possible to interpret such two-stage organic redox systems as Weitz-type redox systems according to Hünig ${ }^{30,31}$ as a chemical equilibrium between the reduced neutral state $(\mathbf{n T})$, radical cation $\left(\mathbf{n} \mathbf{T}^{+}\right)$, and dication $\left(\mathbf{n} \mathbf{T}^{\mathbf{2}+}\right)$ state:

$$
\begin{gathered}
\mathrm{nT}+\mathrm{nT}^{2+} \stackrel{K}{\rightleftarrows} 2 \mathrm{nT}^{+} \\
\log K=\frac{\mathrm{n} \cdot \mathrm{F} \cdot\left(E_{\mathrm{ox}, 2}-E_{\mathrm{ox}, 1}\right)}{\mathrm{R} \cdot T}=\frac{\mathrm{n} \cdot\left(E_{\mathrm{ox}, 2}-E_{\mathrm{ox}, 1}\right)}{0.059}
\end{gathered}
$$

Here $K$ can be understood as a comproportionation constant that defines the thermodynamic stability of the radical cation against disproportionation into the neutral and dicationic closed-shell species. For the $0.25 \mathrm{~V}$ separation observed for 4T, the equilibrium constant $K$ for one-electron oxidations $(n=1)$ at room temperature $(T=298 \mathrm{~K})$ accordingly is 17000 , which is reduced by more than one order of magnitude to $K=1100$ for $\mathbf{5 T}$ and $\mathbf{6 T}$. This trend can be interpreted either as a decreased stabilization of the radical cation or as an increased stabilization of the dication upon chain extension. In contrast to classical Weitz- and Wurster-type redox systems ${ }^{31}$ or organic mixed valence compounds, ${ }^{32}$ the second interpretation is favored in the field of conductive polymers because it suggests that a second positive charge can only be accommodated at reasonably low redox potentials if the oligothiophene chain exhibits a sufficient length to overcome the Coulomb repulsion between the two positive charges. ${ }^{14} \mathrm{~A}$ perfect example for such a case is given with a cyclic oligothiophene consisting of 10 thiophene units that forms with the second oxidation a polaron pair, i.e. this dication is a biradical with a pronounced electron paramagnetic resonance signal. ${ }^{18}$ However, in other situations the second oxidation may involve the same orbital (singly occupied molecular orbital) in a fully conjugated system, leading to a bipolaron (dication without radical character). For classical Weitz-type redox systems as provided by viologens, $K>10^{6}$ was calculated by equation (1) from a larger separation of the two, in this case, reductive waves of $0.40 \mathrm{~V}$ and interpreted as arising from the stabilization of the radical cation by full delocalization of the first (negative) charge across both pyridinium units. ${ }^{33}$ For the vinylogous situation where both pyridinium units are connected by a double bond, a smaller $K$-value of 1000 is calculated by equation (1) from the smaller separation of the two reduction processes by only $0.18 \mathrm{~V},{ }^{34}$ quite similarly as observed in our series of oligothiophenes. This smaller $K$-value according to Hünig is explained by the reduced delocalization of the negative charge across the vinylogous bridge. This explanation could obviously also rationalize the related observations for oligothiophenes in our and earlier studies. Notably, for rigid fully planar $\pi$-scaffolds as given in the series of rylene bisimides, Bard, Müllen and coworkers could even observe the limiting case: thus, whilst a separation of the first and second reduction waves by $0.22 \mathrm{~V}$ for perylene bisimides affords a $K$-value of 5000 , suggesting strong sharing of the negative charge in this radical anion by both imide units, for extended quaterrylene bisimides a single two-electron reduction process is observable for which digital simulation affords a $K$-value of only 5 . Accordingly in this case the two negative charges might be considered as localized on the two respective terminal naphthalimide subunits with little interaction. Clearly, this stage has not yet been reached by the oligothiophenes investigated in our study.

Similar to the optical properties discussed before, two main aspects are expected to dictate the energetics of the first one-electron oxidation process in the 4T-7T series. The degree of conjugation along the $\pi$-system related to the chain length and planarity, as well as the electron-donating influence of the substituents. Firstly, the end-capping by two phenyl moieties greatly enhanced the conjugation length in comparison to entirely unsubstituted $\alpha$-oligothiophenes. ${ }^{25}$ Secondly, the electron-donating effect of four aliphatic $\mathrm{C}_{6} \mathrm{H}_{13}$-chains should lead to lower oxidation potentials compared to the respective unsubstituted $\alpha$-oligothiophenes. Indeed, a comparison of the electrochemical data of 4T and $6 \mathbf{T}$ $\left(E_{\mathrm{ox}, 1}=0.33 \mathrm{~V}\right.$ and $0.16 \mathrm{~V}$, respectively; Table 1$)$ with closely related $\alpha$-sexithiophenes supports the view that the first 
a)

b)

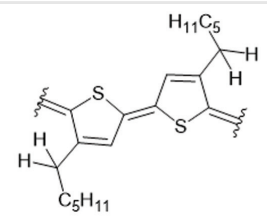

c)

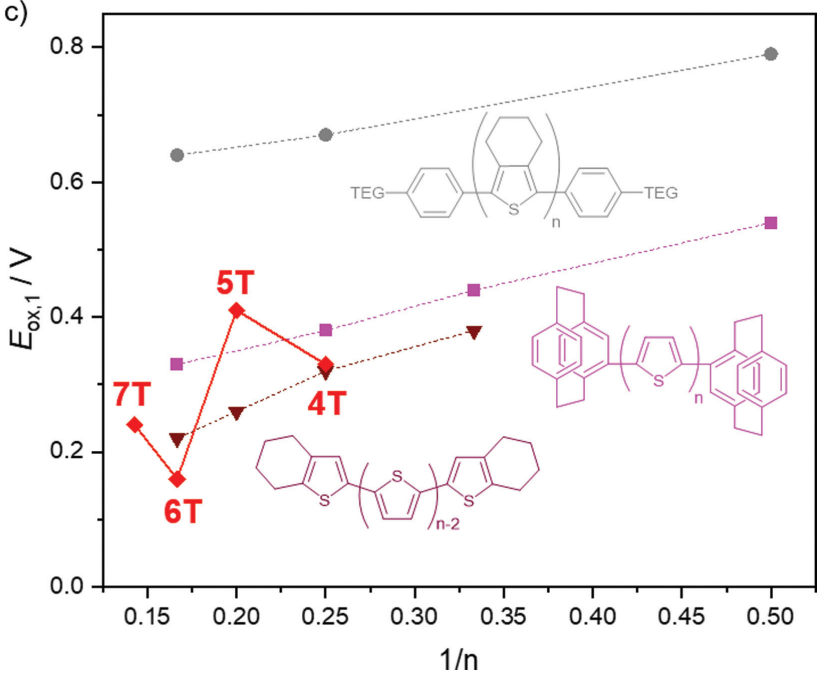

Figure 3 Graphical illustration of the first oxidation potential $E_{\mathrm{ox}, 1} \mathrm{vs}$. the inverse total number of thiophene units $n$ for different end-capped oligothiophenes. The displayed compounds were synthesized by the groups of $\mathrm{Ikeda}^{24}$ (grey), Audebert ${ }^{23}$ (magenta), and Bäuerle ${ }^{22}$ (purple). The red symbols represent the compounds $4 \mathbf{T}-\mathbf{7 T}$ and the lines serve as guide to the eye. All measurements were conducted in $\mathrm{CH}_{2} \mathrm{Cl}_{2}$ solutions at room temperature. TEG = tetraethylene glycol.

oxidation is supported by the combination of the terminal phenyl groups and the alkyl substituents (Figure 3c). Surprisingly, however, a gradual decrease of $E_{\mathrm{ox}, 1}$ is not observed upon extension of the oligothiophene chain in the series 4T-7T. Instead, a zig-zag trend of $E_{\mathrm{ox}, 1}$ is observed with values of $0.33 \mathrm{~V}(\mathbf{4 T}), 0.41 \mathrm{~V}(\mathbf{5 T}), 0.16 \mathrm{~V}(\mathbf{6 T})$, and $0.24 \mathrm{~V}(\mathbf{7 T})$. This observation is clearly opposed to the trends observed for other end-capped $\alpha$-oligothiophene architectures illustrated in Figure 3c that were investigated by the groups of Bäuerle, ${ }^{22}$ Audebert, ${ }^{23}$ and Ikeda ${ }^{24}$ which show a gradual decrease of the first one-electron oxidation potentials $E_{\mathrm{ox}, 1}$ with increasing number of thiophene subunits. This finding has also been supported by theoretical calculations for different unsubstituted $\alpha$-oligothiophenes. ${ }^{35}$

The reason for the unusual behavior observed for our series $\mathbf{4 T}-\mathbf{7 T}$ is presumably attributable to the aforementioned location of the solubilizing alkyl chains. Upon oxidation of the oligothiophene backbone, a more planar quinoidal structure with closer thiophene units (due to the double bond character) is adopted. Such planarization of the entire backbone is particularly needed for the shorter oligomers, i.e. $\mathbf{4 T}$ and $\mathbf{5 T}$, to delocalize the charge along a significant number of thiophene units. However, steric encumbrance of the alkyl chains in $\mathbf{5 T}$ and $\mathbf{7 T}$ (Figure 3a) will countervail a complete planarization due to their close proximity, thereby enforcing a larger contortion and concomitantly destabilization of the radical cationic state. Clearly, whilst also in the absorption and fluorescence spectra (Figure 1 and Figure S1) modest deviations in the bathochromic displacements compared to other oligothiophene series could be observed, e.g. the $\lambda_{\text {abs,max }}$ value increases unsteadily by $9 \mathrm{~nm}$ (4T to $\mathbf{5 T}$ ), $15 \mathrm{~nm}$ (5T to $\mathbf{6 T}$ ), and $7 \mathrm{~nm}$ (6T to $\mathbf{7 T}$ ) (Table 1), this effect is much more pronounced for the oxidation process where the stabilization of the radical cation calls for a higher degree of planarity.

An alternative option to the illustrated trans-transconformation for the oligothiophene backbone where the alkyl $\mathrm{CH}_{2}$ groups suffer from close proximity in the case of $\mathbf{5 T}$ and 7T (Figure 3a) might be a preferential formation of a trans-cis-conformation for these oligothiophenes. However, due to the fact that Bäuerle and co-workers observed lower first oxidation potentials for an all-cis cyclo[10]oligothiophene and attributed this observation to a raised HOMO level in the cis conformation, ${ }^{13}$ we favor the above explanation based on a less planarized conjugated chain.

Different from 5T and 7T, the aliphatic chains in 4T point away from each other and in $\mathbf{6 T}$ (Scheme 1) the hexyl chains are too far apart for any repulsive effects. A representation of the expected situation in a transconformation for molecule $\mathbf{4 T}$ in their radical state is displayed in Figure 3b. Thus, for $\mathbf{4 T}$ and $\mathbf{6 T}$ the oxidation potential is not influenced by sterical encumbrance, enabling a better stabilization of the oxidized more quinoidal state that requires planarity and closer thiophene-thiophene distances due to the double bond character. Notably, a similar zig-zag trend is also observable for the second oxidation process (Table 1), which is, however, more difficult to analyze due to the above-discussed special effects originating from the interactions of the two polarons in multiredox systems.

The impact of such sterical interactions should be taken into account in the design of oligothiophenes. Avoiding such sterical congestions can afford a better stabilization of the quinoid structure and concomitantly lower the oxidation potentials, whilst increasing such sterical congestions might be an approach to isolate multiple radical cations, i.e. to create polaron pair states. Such concepts are currently also applied to create organic biradicals ${ }^{36}$ that are of interest for functional materials for singlet fission. ${ }^{37,38}$

\section{Conclusions}

In conclusion, a new series of phenyl end-capped $\alpha-$ oligothiophenes 4T-7T was synthesized and characterized by UV/Vis absorption and fluorescence spectroscopy as well as electrochemistry. Optical spectroscopy revealed a 
notable bathochromic shift of the absorption maxima compared to nonsubstituted $\alpha$-oligothiophenes that is attributable to the conjugated phenyl substituents. Another more unexpected effect was found that is caused by the position of the alkyl chains. Thus, all electronic states that require planarization of the oligothiophene backbone will be disfavored by sterical encumbrance of close-by positioned alkyl chains. This effect was particularly pronounced for the formation of the radical cations upon electrochemical oxidation, leading to a zig-zag trend for the first one-electron oxidation potential in our series of molecules 4T-7T. Accordingly, the alkyl chain positioning rather than the number of thiophene units determines the electrochemical properties in this series of oligomers. This result could pave the way for an improved electronic fine-tuning of $\alpha$-oligothiophenes as required for various applications in (opto-)electronic devices.

\section{Experimental Section}

\section{Materials and Methods}

All reactions were performed in standard glass equipment. All used chemicals were purchased from commercial suppliers and used without further purification. The reactions were carried out under nitrogen atmosphere. Diethyl ether, THF, and toluene were purified and dried with the commercial purification system PureSolv MD from Innovative Technology. Stille coupling procedures were conducted in additionally degassed toluene.

Preparative column chromatography was performed with self-packed glass columns of several sizes filled with silica gel $60 \mathrm{M}$ (particle size: $0.04-0.063 \mathrm{~mm}$, Merck $K G a A$ ). Dichloromethane was freshly distilled prior to use. Size exclusion chromatography was performed with commercial glass columns using Bio-Beads ${ }^{\circledR}$ (S-X3-Beads, styrene divinylbenzene copolymer, bead size 40-80 $\mu \mathrm{m}$ ) from Bio-Rad as the stationary phase and HPLC grade solvents as the mobile phase. Purification by gel permeation chromatography was performed on a Shimadzu instrument (LC-20AD Prominence Pump, SPD-MA20A Prominence Diode Array Detector) with two preparative columns (Japan Analytical Industries Co., Ltd). Ethanol-stabilized $\mathrm{CHCl}_{3} \quad$ (Chromasolv ${ }^{\circledR}$, Sigma Aldrich) was used as an eluent.

NMR spectra were recorded on a Bruker Avance III HD $400 \mathrm{MHz}$ spectrometer using deuterated solvents. ${ }^{13} \mathrm{C}$ NMR spectra are broad-band proton decoupled. Chemical shifts $(\delta)$ are listed in parts per million (ppm) and coupling constants $(J)$ are listed in hertz $(\mathrm{Hz})$. The spectra are referenced internally to residual proton solvent resonances or natural abundance carbon resonances. Multiplicities are reported as $\mathrm{s}=$ singlet, $\mathrm{d}=$ doublet, $\mathrm{dd}=$ doublet of doublets, $\mathrm{t}=$ triplet, quin $=$ quintet, and $\mathrm{m}=$ multiplet with the chemical shift in the center of the signal.

High-resolution MALDI-TOF mass spectra were recorded with an ultrafleXtreme mass spectrometer (Bruker Daltonics $\mathrm{GmbH}$ ) using DCBT (2-[(2E)-3-(4-tert-butylphenyl)-2-methylprop-2-enylidene]malononitrile) as matrix. The melting points (M.p.) were determined using a Stuart SMP50 automatic melting point apparatus and are uncorrected.

UV/Vis absorption spectra of the solutions were recorded in cuvettes (SUPRASIL ${ }^{\circledR}$, Hellma ${ }^{\circledR}$ Analytics) on a Jasco V-670 or V-770 spectrometer and fluorescence spectra on a FLS980-D2D2-ST fluorescence spectrometer (Edinburgh Instruments) and were corrected against the photomultiplier sensitivity and the lamp intensity. The fluorescence lifetimes were determined via TCSPC utilizing an EPL picosecond pulsed diode laser $\left(\lambda_{\mathrm{ex}}=403.8 \mathrm{~nm}\right)$ with a pulse width of 141.7 ps with a FLS980-D2D2-ST spectrometer (Edinburgh Instruments Ltd., United Kingdom) under magic-angle conditions $\left(54.7^{\circ}\right)$. The fitting of the data was carried out using the reconvolution fit routine supplied by Edinburgh Instruments Ltd., Inc., taking the instrument response function into consideration.

CV and DPV experiments were carried out with a BASi Epsilon potentiostat connected to a microcell apparatus from rhd instruments involving a $1.6 \mathrm{~mL}$ sample container, a platinum counter- and pseudo-reference electrode as well as a glassy carbon working electrode.

\section{Synthesis}

The precursor molecules $1,{ }^{39} \mathbf{3},{ }^{40} \mathbf{5},{ }^{41}$ and (3,3"-dihexyl[2,2':5',2"-terthiophene]-5,5"-diyl)bis[1,1,1-tributylstannane $]^{42}$ were synthesized according to the procedures reported in the literature.

\section{General Procedure for Stannylation Reactions on Oligothiophenes}

To a stirred solution of oligothiophene (1.0 equiv) and tetramethylethylenediamine (TMEDA) (2.1 equiv) in dry THF or Et ${ }_{2} \mathrm{O}, n$-butyllithium ( $n$-BuLi; $1.6 \mathrm{M}$ in $n$-hexane, 3.0 equiv) was added dropwise at $0{ }^{\circ} \mathrm{C}$. The solution was stirred for $1 \mathrm{~h}$ at $0^{\circ} \mathrm{C}$. $\mathrm{Sn}\left(\mathrm{C}_{4} \mathrm{H}_{9}\right)_{3} \mathrm{Cl}$ (4.0 equiv) was added dropwise at $0{ }^{\circ} \mathrm{C}$ and the reaction mixture was stirred at room temperature (r.t.). The reaction was quenched with water and the aqueous layer was extracted three times with $\mathrm{CH}_{2} \mathrm{Cl}_{2}$. The combined organic layers were washed with brine, dried over $\mathrm{MgSO}_{4}$, and the solvent was removed in vacuo. The residue was purified by (flash) column chromatography (deactivated silica gel) using $n$-hexane as eluent to give the desired compounds as pale yellow oils. 
(3',4"'-Di-n-hexyl-[2,2':5',2":5",2"'-quaterthiophene]5,5"'-diyl)bis[1,1,1-tributylstannane] (2)

Oligothiophene 1 ( $60.5 \mathrm{mg}, 121 \mu \mathrm{mol})$, TMEDA $(38.0 \mu \mathrm{L}$, $255 \mu \mathrm{mol}), n$-BuLi $(227 \mu \mathrm{L}, 364 \mu \mathrm{mol}), \operatorname{Sn}\left(\mathrm{C}_{4} \mathrm{H}_{9}\right)_{3} \mathrm{Cl}(132 \mu \mathrm{L}$, $485 \mu \mathrm{mol})$, THF $(10 \mathrm{~mL})$. Addition of $n$-BuLi at $-78{ }^{\circ} \mathrm{C}$, stirring at r.t. for $4 \mathrm{~h}$. Additional purification via size exclusion chromatography $\left(\mathrm{CH}_{2} \mathrm{Cl}_{2} / \mathrm{MeOH}=9: 1\right)$. Yield: $27.6 \mathrm{mg}(25.6 \mu \mathrm{mol}, 21 \%)$, yellow oil. ${ }^{1} \mathrm{H}$ NMR $(400 \mathrm{MHz}$, $\left.\mathrm{CD}_{2} \mathrm{Cl}_{2}, 295 \mathrm{~K}\right): \delta / \mathrm{ppm}=7.25\left(\mathrm{~d},{ }^{3} \mathrm{~J}=3.4 \mathrm{~Hz}, 2 \mathrm{H}\right), 7.13(\mathrm{~d}$, $\left.{ }^{3} \mathrm{~J}=3.4 \mathrm{~Hz}, 2 \mathrm{H}\right), 7.01(\mathrm{~s}, 2 \mathrm{H}), 2.75\left(\mathrm{t},{ }^{3} \mathrm{~J}=7.8 \mathrm{~Hz}, 4 \mathrm{H}\right)$, 1.70-1.55 (m, $16 \mathrm{H}), 1.44-1.30(\mathrm{~m}, 24 \mathrm{H}), 1.22-1.07(\mathrm{~m}$, $12 \mathrm{H}), 0.91\left(\mathrm{t},{ }^{3} \mathrm{~J}=7.3 \mathrm{~Hz}, 24 \mathrm{H}\right) .{ }^{13} \mathrm{C}$ NMR $\left(100 \mathrm{MHz}, \mathrm{CD}_{2} \mathrm{Cl}_{2}\right.$, $295 \mathrm{~K}): \delta / \mathrm{ppm}=141.7,140.3,138.0,136.2,134.7,130.3$, 127.1, 126.8, 32.1, 30.9, 29.8, 29.6, 29.4, 27.7, 23.0, 14.3, 13.8, 11.2. HRMS (MALDI-TOF, positive mode, DCTB in $\mathrm{CHCl}_{3}$ ): $m / z=1078.3651$ (calcd. for $\mathrm{C}_{52} \mathrm{H}_{86} \mathrm{~S}_{4} \mathrm{Sn}_{2}{ }^{+}$: 1078.3656).

(3'",4'-Di-n-hexyl-[2,2':5',2":5",2'":5'",2"'"-quinquethiophene]-5,5"'-diyl)bis[1,1,1-tributylstannane] (4)

Oligothiophene 3 (165 mg, $284 \mu \mathrm{mol})$, TMEDA (770 $\mu \mathrm{L}$, $596 \mu \mathrm{mol}), n$-BuLi $(533 \mu \mathrm{L}, 852 \mu \mathrm{mol}), \operatorname{Sn}\left(\mathrm{C}_{4} \mathrm{H}_{9}\right)_{3} \mathrm{Cl}(310 \mu \mathrm{L}$, $1.14 \mathrm{mmol}), \mathrm{Et}_{2} \mathrm{O}(15 \mathrm{~mL})$. Stirring overnight at r.t. Yield: $308 \mathrm{mg}(266 \mu \mathrm{mol}, 94 \%)$, yellow oil. ${ }^{1} \mathrm{H}$ NMR $(400 \mathrm{MHz}$, $\left.\mathrm{CD}_{2} \mathrm{Cl}_{2}, 295 \mathrm{~K}\right): \delta / \mathrm{ppm}=7.30\left(\mathrm{~d},{ }^{3} \mathrm{~J}=3.4 \mathrm{~Hz}, 2 \mathrm{H}\right), 7.10$ (s, $2 \mathrm{H}), 7.09\left(\mathrm{~d},{ }^{3} \mathrm{~J}=3.4 \mathrm{~Hz}, 2 \mathrm{H}\right), 7.05(\mathrm{~s}, 2 \mathrm{H}), 2.78$ $\left(\mathrm{t},{ }^{3} \mathrm{~J}=7.8 \mathrm{~Hz}, 4 \mathrm{H}\right), 1.73-1.65(\mathrm{~m}, 4 \mathrm{H}), 1.64-1.55(\mathrm{~m}, 12 \mathrm{H})$, $1.47-1.28(\mathrm{~m}, 24 \mathrm{H}), 1.17-1.11(\mathrm{~m}, 12 \mathrm{H}), 0.91\left(\mathrm{t},{ }^{3} \mathrm{~J}=7.3 \mathrm{~Hz}\right.$, $24 \mathrm{H}) .{ }^{13} \mathrm{C}$ NMR $\left(100 \mathrm{MHz}, \mathrm{CD}_{2} \mathrm{Cl}_{2}, 295 \mathrm{~K}\right): \delta / \mathrm{ppm}=142.7$, 141.0, 137.6, 136.7, 136.1, 135.7, 129.3, 126.9, 126.2, 125.2, $32.1, \quad 30.9, \quad 29.9, \quad 29.7,29.3,27.7,23.1,14.3,13.8$, 11.2. HRMS (MALDI-TOF, positive mode, DCTB in $\mathrm{CHCl}_{3}$ ): $m / z=1160.3528$ (calcd. for $\mathrm{C}_{56} \mathrm{H}_{88} \mathrm{Sn}_{2} \mathrm{~S}_{5}^{+}:$1160.3533).

(3',',4'-Di-n-hexyl-

[2,2':5',2":5",2"':5"',2"'”:5",',2",'"-sexithiophene]5,5'”'-diyl)bis[1,1,1-tributylstannane] (6)

Oligothiophene 5 (428 mg, $646 \mu \mathrm{mol}$ ), TMEDA (320 $\mu \mathrm{L}$, $1.36 \mathrm{mmol}), n$-BuLi (1.21 mL, $1.94 \mathrm{mmol}), \mathrm{Sn}\left(\mathrm{C}_{4} \mathrm{H}_{9}\right)_{3} \mathrm{Cl}(132$ $\mu \mathrm{L}, 2.58 \mathrm{mmol}), \mathrm{Et}_{2} \mathrm{O}(25 \mathrm{~mL})$. Addition of $n$-BuLi at $-78^{\circ} \mathrm{C}$, stirring at r.t. for $4 \mathrm{~h}$. Additional purification via size exclusion chromatography $\left(\mathrm{CHCl}_{3} / \mathrm{MeOH}=9: 1\right)$. Yield: $507 \mathrm{mg}(409 \mu \mathrm{mol}, 63 \%)$, yellow oil. ${ }^{1} \mathrm{H}$ NMR $(400 \mathrm{MHz}$, $\left.\mathrm{CD}_{2} \mathrm{Cl}_{2}, 295 \mathrm{~K}\right): \delta / \mathrm{ppm}=7.30\left(\mathrm{~d},{ }^{3} \mathrm{~J}=3.4 \mathrm{~Hz}, 2 \mathrm{H}\right), 7.16(\mathrm{~d}$, $\left.{ }^{3} \mathrm{~J}=3.8 \mathrm{~Hz}, 2 \mathrm{H}\right), 7.09\left(\mathrm{~d},{ }^{3} \mathrm{~J}=3.4 \mathrm{~Hz}, 2 \mathrm{H}\right), 7.07\left(\mathrm{~d},{ }^{3} \mathrm{~J}=3.8\right.$ $\mathrm{Hz}, 2 \mathrm{H}), 7.05$ (s, 2H), 2.78 (t, $\left.{ }^{3} \mathrm{~J}=7.8 \mathrm{~Hz}, 4 \mathrm{H}\right), 1.73-1.55$ (m, 16H), $1.45-1.30(\mathrm{~m}, 24 \mathrm{H}), 1.20-1.08(\mathrm{~m}, 12 \mathrm{H}), 0.91$ $\left(\mathrm{t},{ }^{3} \mathrm{~J}=7.3 \mathrm{~Hz}, 24 \mathrm{H}\right) .{ }^{13} \mathrm{C}$ NMR $\left(100 \mathrm{MHz}, \mathrm{CD}_{2} \mathrm{Cl}_{2}, 295 \mathrm{~K}\right)$ : $\delta / \mathrm{ppm}=142.6,141.1,137.7,136.9,136.7,135.8,135.6$,
129.2, 126.9, 126.6, 125.2, 124.3, 32.1, 30.8, 29.9, 29.6, 29.3, 27.7, 23.0, 14.3, 13.8, 11.2. HRMS (MALDI-TOF, positive mode, DCTB in $\mathrm{CHCl}_{3}$ ): $\mathrm{m} / \mathrm{z}=1242.3405$ (calcd. for $\mathrm{C}_{60} \mathrm{H}_{90} \mathrm{~S}_{6} \mathrm{Sn}_{2}{ }^{+}:$1242.3411).

(3"',,4"'-Di-n-hexyl-[2,2':5',2":5",2"':5"',2"'":

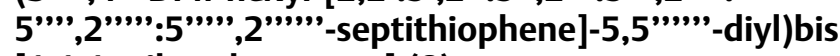
[1,1,1-tributylstannane] (8)

Oligothiophene 7 (620 mg, $832 \mu \mathrm{mol}$ ), TMEDA ( $262 \mu \mathrm{L}$, $1.75 \mathrm{mmol}), n$-BuLi $(1.56 \mathrm{~mL}, 2.50 \mathrm{mmol}), \quad \mathrm{Sn}\left(\mathrm{C}_{4} \mathrm{H}_{9}\right)_{3} \mathrm{Cl}$ (903 $\mu \mathrm{L}, 3.33 \mathrm{mmol}), \mathrm{Et}_{2} \mathrm{O}(15 \mathrm{~mL})$. Stirring overnight at $\mathrm{r}$. t. Purification via column chromatography (deactivated silica gel, cyclohexane $\mathrm{CH}_{2} \mathrm{Cl}_{2}=5: 1$ ). Yield: $362 \mathrm{mg}$ (274 $\mu \mathrm{mol}, 33 \%)$, yellow oil. ${ }^{1} \mathrm{H}$ NMR $\left(400 \mathrm{MHz}, \mathrm{CD}_{2} \mathrm{Cl}_{2}\right.$, $295 \mathrm{~K}): \delta / \mathrm{ppm}=7.31\left(\mathrm{~d},{ }^{3} \mathrm{~J}=3.4 \mathrm{~Hz}, 2 \mathrm{H}\right), 7.12(\mathrm{~s}, 2 \mathrm{H}), 7.10$ $(\mathrm{s}, 4 \mathrm{H}), 7.06(\mathrm{~s}, 2 \mathrm{H}), 7.09\left(\mathrm{~d},{ }^{3} \mathrm{~J}=3.4 \mathrm{~Hz}, 2 \mathrm{H}\right), 2.79$ $\left(\mathrm{t},{ }^{3} \mathrm{~J}=7.8 \mathrm{~Hz}, 4 \mathrm{H}\right), 1.73-1.65(\mathrm{~m}, 4 \mathrm{H}), 1.64-1.55(\mathrm{~m}, 12 \mathrm{H})$, $1.47-1.28(\mathrm{~m}, 24 \mathrm{H}), 1.17-1.11(\mathrm{~m}, 12 \mathrm{H}), 0.91\left(\mathrm{t},{ }^{3} \mathrm{~J}=7.3 \mathrm{~Hz}\right.$, $24 \mathrm{H}) .{ }^{13} \mathrm{C}$ NMR $\left(100 \mathrm{MHz}, \mathrm{CD}_{2} \mathrm{Cl}_{2}, 295 \mathrm{~K}\right): \delta / \mathrm{ppm}=142.6$, 141.1, 137.9, 137.0, 136.7, 136.1, 135.7, 135.2, 129.7, 127.0, 126.4, 125.3, 124.7, 124.5, 32.1, 30.9, 29.9, 29.7, 29.3, 27.7, 23.0, 14.3, 13.8, 11.2. HRMS (MALDI-TOF, positive mode, DCTB in $\mathrm{CHCl}_{3}$ ): $\mathrm{m} / z=1324.3282$ (calcd. for $\mathrm{C}_{64} \mathrm{H}_{92} \mathrm{Sn}_{2} \mathrm{~S}_{7}{ }^{+}$: 1324.3288).

\section{General Procedure for Stille Coupling Reactions}

Stannylated precursors (1.0 equiv), the respective bromo compounds (2.5 equiv), $\left[\mathrm{Pd}_{2}(\mathrm{dba})_{3}\right](5 \mathrm{~mol} \%)$, and tris ( $o$-tolyl) phosphine ( $11 \mathrm{~mol} \%$ ) were dissolved in degassed toluene and stirred overnight at $95{ }^{\circ} \mathrm{C}$. The solution was allowed to cool down to r.t. and the solvent was removed in vacuo.

\section{3"',,4"'-Di-n-hexyl-2,2':5',2":5",2"':5"',2"'”:5"',,2"'”: 5 ",',2,"','-septithiophene (7)}

(3,3"-Dihexyl-[2,2':5',2"-terthiophene]-5,5"-diyl)bis [1,1,1-tributylstannane] (919 mg, $924 \mu \mathrm{mol}), 5$-bromo-2,2'bithiophene (566 mg, $2.31 \mathrm{mmol}),\left[\mathrm{Pd}_{2} \mathrm{dba}_{3}\right](42.3 \mathrm{mg}$, $46.2 \mu \mathrm{mol}), \mathrm{P}(0 \text {-tolyl })_{3}(31.0 \mathrm{mg}, 102 \mu \mathrm{mol})$, toluene (30 mL). Purification via column chromatography (gradient of cyclohexane $/ \mathrm{CH}_{2} \mathrm{Cl}_{2}=5: 1$ to cyclohexane $/ \mathrm{CH}_{2} \mathrm{Cl}_{2}=1: 1$ ). Yield: $604 \mathrm{mg}(811 \mu \mathrm{mol}, 88 \%)$, orange solid. M.p. $=162-$ $163{ }^{\circ} \mathrm{C} .{ }^{1} \mathrm{H}$ NMR $\left(400 \mathrm{MHz}, \mathrm{CD}_{2} \mathrm{Cl}_{2}, 295 \mathrm{~K}\right): \delta / \mathrm{ppm}=7.26$ $\left(\mathrm{dd},{ }^{3} \mathrm{~J}=5.1 \mathrm{~Hz},{ }^{4} \mathrm{~J}=1.2 \mathrm{~Hz}, 2 \mathrm{H}\right), 7.21\left(\mathrm{dd},{ }^{3} \mathrm{~J}=3.7 \mathrm{~Hz}\right.$, $\left.{ }^{4} \mathrm{~J}=1.2 \mathrm{~Hz}, 2 \mathrm{H}\right), 7.12\left(\mathrm{~d},{ }^{3} \mathrm{~J}=3.8 \mathrm{~Hz}, 2 \mathrm{H}\right), 7.12(\mathrm{~s}, 2 \mathrm{H}), 7.11$ $\left(\mathrm{d},{ }^{3} \mathrm{~J}=3.8 \mathrm{~Hz}, 2 \mathrm{H}\right), 7.07$ (s, $\left.2 \mathrm{H}\right), 7.05\left(\mathrm{~d},{ }^{3} \mathrm{~J}=5.1 \mathrm{~Hz}, 2 \mathrm{H}\right)$, $2.79\left(\mathrm{t},{ }^{3} \mathrm{~J}=7.9 \mathrm{~Hz}, 4 \mathrm{H}\right), 1.69$ (quin, ${ }^{3} \mathrm{~J}=7.3 \mathrm{~Hz}, 4 \mathrm{H}$ ), $1.46-$ $1.30(\mathrm{~m}, 12 \mathrm{H}), 0.90\left(\mathrm{t},{ }^{3} \mathrm{~J}=7.1 \mathrm{~Hz}, 6 \mathrm{H}\right) .{ }^{13} \mathrm{C}$ NMR $(100 \mathrm{MHz}$, $\left.\mathrm{CD}_{2} \mathrm{Cl}_{2}, 295 \mathrm{~K}\right): \delta / \mathrm{ppm}=141.1,137.3,136.6,136.2,136.1$, 
135.1, 129.8, 128.4, 127.2, 126.4, 125.1, 124.8. 124.7, 124.2, 32.1, 30.9, 29.9, 29.7, 23.0, 14.3. HRMS (MALDI-TOF, positive mode, DCTB in $\mathrm{CHCl}_{3}$ ): $\mathrm{m} / z=744.1169$ (calcd. for $\mathrm{C}_{40} \mathrm{H}_{40} \mathrm{~S}_{7}^{+}$: 744.1175).

\section{5,5'"-Bis(3-n-hexylphenyl)-3',4"'-di-n-hexyl-} 2,2':5',2":5",2'"'-quaterthiophene (4T)

Stannylated oligothiophene $2(23.3 \mathrm{mg}, 21.6 \mu \mathrm{mol})$, 1-bromo-3-hexylbenzene (13.1 mg, $54.1 \mu \mathrm{mol})$, $\left[\mathrm{Pd}_{2} \mathrm{dba}_{3}{ }^{*} \mathrm{CHCl}_{3}\right] \quad(1.12 \mathrm{mg}, \quad 1.08 \mu \mathrm{mol}), \quad \mathrm{P}(o \text {-tolyl })_{3}$ (0.73 mg, $2.38 \mu \mathrm{mol})$, toluene $(10 \mathrm{~mL})$. Purification via flash column chromatography (gradient of cyclohexane to cyclohexane $\left./ \mathrm{CH}_{2} \mathrm{Cl}_{2}=5: 1\right)$ and gel permeation chromatography $\left(\mathrm{CHCl}_{3}\right)$. Yield: $6.1 \mathrm{mg}(7.45 \mu \mathrm{mol}, 34 \%)$, orange solid. M.p. $=86-87{ }^{\circ} \mathrm{C} .{ }^{1} \mathrm{H}$ NMR $\left(400 \mathrm{MHz}, \mathrm{CD}_{2} \mathrm{Cl}_{2}, 295 \mathrm{~K}\right): \delta /$ $\mathrm{ppm}=7.42-7.47(\mathrm{~m}, 4 \mathrm{H}), 7.31\left(\mathrm{t},{ }^{3} \mathrm{~J}=7.5 \mathrm{~Hz}, 2 \mathrm{H}\right), 7.31$ (d, $\left.{ }^{3} \mathrm{~J}=3.8 \mathrm{~Hz}, 2 \mathrm{H}\right), 7.16-7.12(\mathrm{~m}, 4 \mathrm{H}), 7.06(\mathrm{~s}, 2 \mathrm{H}), 2.80$ $\left(\mathrm{t},{ }^{3} \mathrm{~J}=7.8 \mathrm{~Hz}, 4 \mathrm{H}\right), 2.65\left(\mathrm{t},{ }^{3} \mathrm{~J}=7.7 \mathrm{~Hz}, 4 \mathrm{H}\right), 1.75-1.60$ (m, $8 \mathrm{H}), 1.45-1.29(\mathrm{~m}, 24 \mathrm{H}), 0.94-0.87(\mathrm{~m}, 12 \mathrm{H}) .{ }^{13} \mathrm{C}$ NMR $\left(100 \mathrm{MHz}, \mathrm{CD}_{2} \mathrm{Cl}_{2}, 295 \mathrm{~K}\right): \delta / \mathrm{ppm}=144.6,144.3,141.0$, 135.5, 135.0, 134.2, 130.1, 129.2, 128.3, 127.1, 127.0, 126.0, 123.8, 123.2, 36.3, 32.1, 32.1, 32.0, 30.8, 30.1, 29.9, 29.6, 29.4, 23.0, 14.3. HRMS (MALDI-TOF, positive mode, DCTB in $\mathrm{CHCl}_{3}$ ): $m / z=818.4042$ (calcd. for $\mathrm{C}_{52} \mathrm{H}_{66} \mathrm{~S}_{4}{ }^{+}$: 818.4047). UV/Vis $\left(\mathrm{CH}_{2} \mathrm{Cl}_{2}, c=50 \mu \mathrm{M}\right): \lambda_{\max }[\mathrm{nm}]\left(\varepsilon_{\max }\left[\mathrm{M}^{-1} \mathrm{~cm}^{-1}\right]\right)$ : 413 (44800). Fluorescence $\left(\mathrm{CH}_{2} \mathrm{Cl}_{2}\right) \lambda_{\text {em }}[\mathrm{nm}]\left(\lambda_{\mathrm{ex}}[\mathrm{nm}]\right)$ : $505 \mathrm{~nm}(400 \mathrm{~nm})$. PLQY $\left(\mathrm{CH}_{2} \mathrm{Cl}_{2}\right): \Phi_{\mathrm{fl}}[\%]=40$.

\section{5,5"''-Bis(3-n-hexylphenyl)-3"',4'-di-n-hexyl-} 2,2':5',2":5",2"':5"',2"'"-quinquethiophene (5T)

Stannylated oligothiophene 4 (110 mg, $94.9 \mu \mathrm{mol},), 1-$ bromo-3-hexylbenzene $(57.4 \mathrm{mg}, 238 \mu \mathrm{mol}),\left[\mathrm{Pd}_{2} \mathrm{dba}_{3}\right]$ (4.34 mg, $4.75 \mu \mathrm{mol}), \mathrm{P}(\text { o-tolyl })_{3}(3.18 \mathrm{mg}, 10.4 \mu \mathrm{mol})$, toluene $(30 \mathrm{~mL})$. Purification via column chromatography (cyclohexane $/ \mathrm{CH}_{2} \mathrm{Cl}_{2}=5: 1$ ) reprecipitation from $\mathrm{CH}_{2} \mathrm{Cl}_{2}$ and $\mathrm{MeOH}$. Yield: $60.0 \mathrm{mg}(66.6 \mu \mathrm{mol}, 70 \%)$, red solid. $\mathrm{M}$. p. $=112-113{ }^{\circ} \mathrm{C} .{ }^{1} \mathrm{H}$ NMR $\left(400 \mathrm{MHz}, \mathrm{CD}_{2} \mathrm{Cl}_{2}, 295 \mathrm{~K}\right)$ : $\delta / \mathrm{ppm}=7.46-7.41(\mathrm{~m}, 4 \mathrm{H}), 7.30\left(\mathrm{t},{ }^{3} \mathrm{~J}=7.5 \mathrm{~Hz}, 2 \mathrm{H}\right)$, $7.27\left(\mathrm{~d},{ }^{3} \mathrm{~J}=3.8 \mathrm{~Hz}, 2 \mathrm{H}\right), 7.17\left(\mathrm{~d},{ }^{3} \mathrm{~J}=3.8 \mathrm{~Hz}, 2 \mathrm{H}\right), 7.15-$ $7.13(\mathrm{~m}, 2 \mathrm{H}), 7.13$ (s, $2 \mathrm{H}), 7.09(\mathrm{~s}, 2 \mathrm{H}), 2.80\left(\mathrm{t},{ }^{3} \mathrm{~J}=7.8 \mathrm{~Hz}, 4\right.$ $\mathrm{H}), 2.65\left(\mathrm{t},{ }^{3} \mathrm{~J}=7.7 \mathrm{~Hz}, 4 \mathrm{H}\right), 1.75-1.60(\mathrm{~m}, 8 \mathrm{H}), 1.45-1.29$ $(\mathrm{m}, 24 \mathrm{H}), 0.94-0.87(\mathrm{~m}, 12 \mathrm{H}) .{ }^{13} \mathrm{C}$ NMR $\left(100 \mathrm{MHz}, \mathrm{CD}_{2} \mathrm{Cl}_{2}\right.$, $295 \mathrm{~K}): \delta / \mathrm{ppm}=144.3,143.8,141.1,136.5,136.1,135.5$, 134.1, 129.7, 129.2, 128.3, 127.0, 126.4, 126.0, 124.9, 124.2, 123.2, 36.3, 32.1 (2 signals), 31.9, 30.9, 29.9, 29.7, 29.4, 23.1, 23.0, 14.3 (2 signals). HRMS (MALDI-TOF, positive mode, DCTB in $\mathrm{CHCl}_{3}$ ): $m / z=900.3919$ (calcd. for $\mathrm{C}_{56} \mathrm{H}_{68} \mathrm{~S}_{5}{ }^{+}$: 900.3925). UV/Vis $\left(\mathrm{CH}_{2} \mathrm{Cl}_{2}, c=50 \mu \mathrm{M}\right): \lambda_{\max }[\mathrm{nm}]\left(\varepsilon_{\max }\right.$ $\left.\left[\mathrm{M}^{-1} \mathrm{~cm}^{-1}\right]\right): 422(54600)$. Fluorescence $\left(\mathrm{CH}_{2} \mathrm{Cl}_{2}\right) \lambda_{\mathrm{em}}[\mathrm{nm}]$ $\left(\lambda_{\text {ex }}[\mathrm{nm}]\right): 526$ (400). PLQY $\left(\mathrm{CH}_{2} \mathrm{Cl}_{2}\right): \Phi_{\mathrm{fl}}[\%]=53$.

\section{5,5'"'-Bis(3-n-hexylphenyl)-3'"',4'-di-n-hexyl- [2,2':5',2":5",2"':5"',2"'”:5"',2,"''-sexithiophene (6T)}

Stannylated oligothiophene 6 (507 mg, $409 \mu \mathrm{mol})$, 1bromo-3-hexylbenzene (246 mg, $1.02 \mathrm{mmol}),\left[\mathrm{Pd}_{2} \mathrm{dba}_{3}\right]$ (18.7 mg, $20.4 \mu \mathrm{mol}), \mathrm{P}(\text { o-tolyl })_{3}(13.7 \mathrm{mg}, 44.9 \mu \mathrm{mol})$, toluene $(15 \mathrm{~mL})$. Purification via filtration through a pad of celite using cyclohexane and subsequent size exclusion chromatography $\left(\mathrm{CH}_{2} \mathrm{Cl}_{2} / \mathrm{MeOH}=9: 1\right)$. Yield: $44.4 \mathrm{mg}$ (45.1 $\mu \mathrm{mol}, 11 \%$ ), red solid. M.p. $=134-135{ }^{\circ} \mathrm{C} .{ }^{1} \mathrm{H}$ NMR $\left(400 \mathrm{MHz}, \mathrm{CD}_{2} \mathrm{Cl}_{2}, 295 \mathrm{~K}\right): \delta / \mathrm{ppm}=7.46-7.41(\mathrm{~m}, 4 \mathrm{H})$, $7.30\left(\mathrm{t},{ }^{3} \mathrm{~J}=7.5 \mathrm{~Hz}, 2 \mathrm{H}\right), 7.27\left(\mathrm{~d},{ }^{3} \mathrm{~J}=3.8 \mathrm{~Hz}, 2 \mathrm{H}\right), 7.19$ (d, $\left.{ }^{3} \mathrm{~J}=3.8 \mathrm{~Hz}, 2 \mathrm{H}\right), 7.17\left(\mathrm{~d},{ }^{3} \mathrm{~J}=3.8 \mathrm{~Hz}, 2 \mathrm{H}\right), 7.15-7.13$ $(\mathrm{m}, 2 \mathrm{H}), 7.10\left(\mathrm{~d},{ }^{3} \mathrm{~J}=3.8 \mathrm{~Hz}, 2 \mathrm{H}\right), 7.09(\mathrm{~s}, 2 \mathrm{H}), 2.80$ $\left(\mathrm{t},{ }^{3} \mathrm{~J}=7.8 \mathrm{~Hz}, 4 \mathrm{H}\right), 2.65\left(\mathrm{t},{ }^{3} \mathrm{~J}=7.7 \mathrm{~Hz}, 4 \mathrm{H}\right), 1.75-1.60$ (m, 8H), 1.45-1.29 (m, 24 H), 0.94-0.87 (m, $12 \mathrm{H}) .{ }^{13} \mathrm{C}$ NMR $\left(100 \mathrm{MHz}, \mathrm{CD}_{2} \mathrm{Cl}_{2}, 295 \mathrm{~K}\right): \delta / \mathrm{ppm}=144.3,143.9,141.2$, 137.0, 136.4, 135.5, 135.4, 134.1, 129.6, 129.2, 128.3, 127.0, 126.8, 126.0, 124.9, 124.4, 124.2, 123.2, 36.3, 32.1 (2 signals), $31.9, \quad 30.8, \quad 29.9, \quad 29.6,29.4,23.0,14.3$ (2 signals). HRMS (MALDI-TOF, positive mode, DCTB in $\mathrm{CHCl}_{3}$ ): $m / z=982.3796$. (calcd. for $\mathrm{C}_{60} \mathrm{H}_{70} \mathrm{~S}_{6}{ }^{+}:$982.3802). UV/Vis $\left(\mathrm{CH}_{2} \mathrm{Cl}_{2}, c=50 \mu \mathrm{M}\right): \lambda_{\max }[\mathrm{nm}]\left(\varepsilon_{\max }\left[\mathrm{M}^{-1} \mathrm{~cm}^{-1}\right]\right): 437$ (62300). Fluorescence $\left(\mathrm{CH}_{2} \mathrm{Cl}_{2}\right) \lambda_{\text {em }}[\mathrm{nm}]\left(\lambda_{\text {ex }}[\mathrm{nm}]\right): 538$ (400). PLQY $\left(\mathrm{CH}_{2} \mathrm{Cl}_{2}\right): \Phi_{\mathrm{fl}}[\%]=49$.

\section{5,5'"',-Bis(3-n-hexylphenyl)-3'"',4"'-di-n-hexyl-

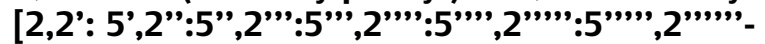 septithiophene (7T)}

Stannylated oligothiophene 8 (350 mg, $264 \mu \mathrm{mol}$ ), 1bromo-3-hexylbenzene (159 mg, $661 \mu \mathrm{mol}),\left[\mathrm{Pd}_{2} \mathrm{dba}_{3}\right]$ (12.1 mg, $13.2 \mu \mathrm{mol}), \mathrm{P}\left(\right.$ o-tolyl) ${ }_{3}(8.86 \mathrm{mg}, 29.1 \mu \mathrm{mol})$, toluene $(40 \mathrm{~mL})$. Purification via flash column chromatography (gradient of cyclohexane to cyclohexane/ $\left.\mathrm{CH}_{2} \mathrm{Cl}_{2}=10: 1\right)$ and gel permeation chromatography $\left(\mathrm{CHCl}_{3}\right)$. Yield: $5.0 \mathrm{mg}(4.69 \mu \mathrm{mol}, 2 \%)$, red solid. M.p. $=157-158{ }^{\circ} \mathrm{C} .{ }^{1} \mathrm{H}$ NMR $\left(400 \mathrm{MHz}, \mathrm{CD}_{2} \mathrm{Cl}_{2}, 295 \mathrm{~K}\right)$ : $\delta / \mathrm{ppm}=7.46-7.41(\mathrm{~m}, 4 \mathrm{H}), 7.30\left(\mathrm{t},{ }^{3} \mathrm{~J}=7.5 \mathrm{~Hz}, 2 \mathrm{H}\right)$, $7.27\left(\mathrm{~d},{ }^{3} \mathrm{~J}=3.8 \mathrm{~Hz}, 2 \mathrm{H}\right), 7.19\left(\mathrm{~d},{ }^{3} \mathrm{~J}=3.8 \mathrm{~Hz}, 2 \mathrm{H}\right), 7.15-$ $7.12(\mathrm{~m}, 8 \mathrm{H}), 7.08(\mathrm{~s}, 2 \mathrm{H}), 2.80\left(\mathrm{t},{ }^{3} \mathrm{~J}=7.8 \mathrm{~Hz}, 4 \mathrm{H}\right), 2.65$ $\left(\mathrm{t},{ }^{3} \mathrm{~J}=7.7 \mathrm{~Hz}, 4 \mathrm{H}\right), 1.75-1.60(\mathrm{~m}, 8 \mathrm{H}), 1.45-1.29(\mathrm{~m}, 24$ $\mathrm{H}), 0.94-0.87(\mathrm{~m}, 12 \mathrm{H}) .{ }^{13} \mathrm{C}$ NMR $\left(100 \mathrm{MHz}, \mathrm{CD}_{2} \mathrm{Cl}_{2}\right.$, $295 \mathrm{~K}): \delta / \mathrm{ppm}=144.4,144.0,141.2,136.6,136.4,136.2$, $136.1,135.1,134.1,129.9,129.2,128.4,127.2,126.5$, 126.0, 125.0, 124.7 (2 signals), 124.2, 123.2, 36.3, 32.1, $32.1,31.9,30.9,29.9,29.7,29.4,23.05,23.03,14.3$ (2 signals). HRMS (MALDI-TOF, positive mode, DCTB in $\mathrm{CHCl}_{3}$ ): $\quad m / z=1064.3674$ (calcd. for $\mathrm{C}_{64} \mathrm{H}_{72} \mathrm{~S}_{7}{ }^{+}$: 1064.3679). UV/Vis $\left(\mathrm{CH}_{2} \mathrm{Cl}_{2}, c=50 \mu \mathrm{M}\right): \lambda_{\max }[\mathrm{nm}]$ $\left(\varepsilon_{\max }\left[\mathrm{M}^{-1} \mathrm{~cm}^{-1}\right]\right): 444(69300)$. Fluorescence $\left(\mathrm{CH}_{2} \mathrm{Cl}_{2}\right)$ $\lambda_{\mathrm{em}}[\mathrm{nm}]\left(\lambda_{\mathrm{ex}}[\mathrm{nm}]\right): 551$ (400), PLQY $\left(\mathrm{CH}_{2} \mathrm{Cl}_{2}\right): \Phi_{\mathrm{fl}}$ $[\%]=46$. 


\section{Acknowledgment}

F.W. thanks Peter Bäuerle for introducing him into chemical research with the fascinating research topic of thiophene electropolymerization in his practical course at the Universität Stuttgart in 1989 and later on into the wider field of organic electronics.

\section{Supporting Information}

Supporting information for this article is available online at https://doi.org/10.1055/s-0041-1726089.

\section{References}

(1) Roncali, J. Chem. Rev. 1997, 97, 173.

(2) Anthony, J. E. Angew. Chem. Int. Ed. 2008, 47, 452.

(3) Mishra, A.; Ma, C.-Q.; Bäuerle, P. Chem. Rev. 2009, 109, 1141.

(4) Roncali, J.; Blanchard, P.; Frere, P. J. Mater. Chem. 2005, 15, 1589.

(5) Shi, H.; Liu, C. C.; Jiang, Q. L.; Xu, J. K. Adv. Electron. Mater. 2015, 1, 1500017.

(6) Ong, B. S.; Wu, Y.; Li, Y.; Liu, P.; Pan, H. Chem. Eur.J. 2008, 14, 4766.

(7) Mishra, A.; Bäuerle, P. Angew. Chem. Int. Ed. 2012, 51, 2020.

(8) Bäuerle, P.; Gaudl, K.; Würthner, F.; Sariciftci, S.; Neugebauer, H.; Mehring, M.; Zhong, C.; Doblhofer, K. Adv. Mater. 1990, 2, 490.

(9) Bäuerle, P.; Würthner, F.; Götz, G.; Effenberger, F.Synthesis 1993, 1099.

(10) Barbarella, G.; Zambianchi, M.; del Fresno, I.; Marimon, M.; Antolini, L.; Bongini, A. Adv. Mater. 1993, 5, 834.

(11) Mena-Osteritz, E.; Meyer, A.; Langeveld-Voss, B. M. W.; Janssen, R. A. J.; Meijer, E. W.; Bäuerle, P. Angew. Chem. Int. Ed. 2000, 39, 2679.

(12) Krömer, J.; Rios-Carreras, I.; Fuhrmann, G.; Musch, C.; Wunderlin, M.; Debaerdemaeker, T.; Mena-Osteritz, E.; Bäuerle, P. Angew. Chem. Int. Ed. 2000, 39, 3481.

(13) Zhang, F.; Götz, G.; Winkler, H. D. F.; Schalley, C. A.; Bäuerle, P. Angew. Chem. Int. Ed. 2009, 48, 6632.

(14) Facchetti, A.; Yoon, M.-H.; Stern, C. L.; Hutchison, G. R.; Ratner, M. A.; Marks, T. J. J. Am. Chem. Soc. 2004, 126, 13480.

(15) Diaz-Quijada, G. A.; Weinberg, N.; Holdcroft, S.; Pinto, B. M. J. Phys. Chem. A 2002, 106, 1266.

(16) Azumi, R.; Mena-Osteritz, E.; Boese, R.; Benet-Buchholz, J.; Bäuerle, P. J. Mater. Chem. 2006, 16, 728.
(17) Heinze, J.; Bilger, R.; Meerholz, K. Ber. Bunsen Ges. Phys. Chem. 1988, 92, 1266.

(18) Zhang, F.; Götz, G.; Mena-Osteritz, E.; Weil, M.; Sarkar, B.; Kaim, W.; Bäuerle, P. Chem. Sci. 2011, 2, 781.

(19) Zhang, L.; Colella, N. S.; Cherniawski, B. P.; Mannsfeld, S. C. B.; Briseno, A. L. ACS Appl. Mater. Interfaces 2014, 6, 5327.

(20) Bäuerle, P.; Pfau, F.; Schlupp, H.; Würthner, F.; Gaudl, K.-U.; Balparda Cara, M.; Fischer, P. J. Chem. Soc., Perkin Trans. 21993 489.

(21) Würthner, F.; Schmidt, R. ChemPhysChem 2006, 7, 793.

(22) Bäuerle, P.; Segelbacher, U.; Maier, A.; Mehring, M. J. Am. Chem. Soc. 1993, 115, 10217.

(23) Guyard, L.; Dumas, C.; Miomandre, F.; Pansu, R.; RenaultMéallet, R.; Audebert, P. New J. Chem. 2003, 27, 1000.

(24) Zheng, Y.; Ohto, T.; Liu, D.; Butt, H.-J.; Ikeda, T. Synth. Met. 2013, $181,1$.

(25) Nikoofard, H.; Gholami, M. C. R. Chim. 2014, 17, 1034.

(26) Bäuerle, P.; Fischer, P.; Bidlingmeier, B.; Stabel, A.; Rabe, J. P. Angew. Chem. Int. Ed. Engl. 1995, 34, 303.

(27) Brouwer, A. M. Pure Appl. Chem. 2011, 83, 2213.

(28) Englman, R.; Jortner, J. Mol. Phys. 1970, 18, 145.

(29) Bäuerle, P.; Segelbacher, U.; Gaudl, K.-U.; Huttenlocher, D.; Mehring, M. Angew. Chem. Int. Ed. Engl. 1993, 32, 76.

(30) Deuchert, K.; Hünig, S. Angew. Chem. Int. Ed. Engl. 1978, 17, 875.

(31) Hünig, S. Pure Appl. Chem. 1990, 62, 395.

(32) Heckmann, A.; Lambert, C. Angew. Chem. Int. Ed. 2012, 51, 326.

(33) Hünig, S.; Schenk, W. Liebigs Ann. Chem. 1979, 1523.

(34) Hesse, K.; Hünig, S. Liebigs Ann. Chem. 1985, 708.

(35) Camarada, M. B.; Jaque, P.; Díaz, F. R.; del Valle, M. A.J. Polym. Sci., Part B, Polym. Phys. 2011, 49, 1723.

(36) Rausch, R.; Röhr, M. I. S.; Schmidt, D.; Krummenacher, I.; Braunschweig, H.; Würthner, F. Chem. Sci. 2021, 12, 793.

(37) Pun, A. B.; Asadpoordarvish, A.; Kumarasamy, E.; Tayebjee, M. J. Y.; Niesner, D.; McCamey, D. R.; Sanders, S. N.; Campos, L. M.; Sfeir, M. Y. Nat. Chem. 2019, 11, 821.

(38) Bialas, D.; Kirchner, E.; Röhr, M.; Würthner, F. J. Am. Chem. Soc. 2021, in press.

(39) Takahashi, M.; Masui, K.; Sekiguchi, H.; Kobayashi, N.; Mori, A.; Funahashi, M.; Tamaoki, N. J. Am. Chem. Soc. 2006, 128, 10930.

(40) L. Jones, C.; J. Higgins, S. J. Mater. Chem. 1999, 9, 865.

(41) Kiriy, N.; Kiriy, A.; Bocharova, V.; Stamm, M.; Richter, S.; Plötner, M.; Fischer, W.-J.; Krebs, F. C.; Senkovska, I.; Adler, H.-J. Chem. Mater. 2004, 16, 4757.

(42) Sato, M.-A.; Fukui, K. Synth. Met. 2007, 157, 619. 